\title{
Implementing Public Health Regulations in Developing Countries: Lessons from the OECD Countries
}

\author{
Lawrence O. Gostin \\ Georgetown University Law Center, gostin@law.georgetown.edu \\ Emily A. Mok \\ Georgetown University Law Center, eam223@law.georgetown.edu \\ Monica Das Gupta \\ World Bank - Development Research Group (DECRG) \\ Max Levin \\ Georgetown University Law Center, mc179@law.georgetown.edu
}

Georgetown Public Law and Legal Theory Research Paper No. 10-68

This paper can be downloaded free of charge from:

https://scholarship.law.georgetown.edu/facpub/470

http://ssrn.com/abstract=1703456

38(3) J. Law, Med. \& Ethics 508-519 (Fall 2010)

This open-access article is brought to you by the Georgetown Law Library. Posted with permission of the author. Follow this and additional works at: https://scholarship.law.georgetown.edu/facpub

Part of the Administrative Law Commons, Health Law and Policy Commons, and the International Law Commons 


\section{Implementing Public Health Regulations in Developing Countries: Lessons from the OECD Countries}

\author{
Emily A. Mok, Lawrence O. \\ Gostin, Monica Das Gupta, and \\ Max Levin
}

\section{Introduction}

Public health agencies undertake a broad range of health promotion and injury and disease prevention activities in collaboration with an array of actors, such as the community, businesses, and non-profit organizations. These activities are "multisectoral" in nature and centered on public health agencies that oversee and engage with the other actors. ${ }^{1}$ Public health agencies can influence the hazardous activities in the private sector in a variety of ways, "ranging from prohibition and regulation to volunteerism, and from cooperation to cooption." ${ }^{2}$ Hence, a public health agency that possesses the necessary administrative resources and authority is vital to the effective implementation of health policies and regulations. ${ }^{3}$

In the developing world, however, many state health agencies lack these basic capacities in dealing with critical health threats, including their ability to avert epidemics of communicable diseases arising from poor sanitary conditions. A serious constraint is the shortage of public health funding for health agencies in the developing world for typical agency functions (e.g., surveillance, monitoring, assessment, and intervention). This is often aggravated by the transactionintensive demands entailed in enforcing regulations among an array of private and public sector actors including individuals, businesses, and local bodies responsible for providing civic services. This combination of constraints makes it difficult for agencies to use their limited funding and personnel to meet compel-

Emily A. Mok, M.G.A., M.B.E., D.Phil. Candidate, is a fellow of the O'Neill Institute for National and Global Health Law and an Adjunct Professor of Law at Georgetown University Law Center. She received dual Master degrees in Government Administration and Bioethics from the University of Pennsylvania, Philadelphia, PA, and is completing her D.Phil. in Law at the University of Oxford in Oxford, U.K. Lawrence O. Gostin, J.D., LL.D. (Hon.), is the Linda D. and Timothy J. O'Neill Professor of Global Health Law, the Faculty Director of the O'Neill Institute for National and Global Health Law, and a Professor of Public Health at the Johns Hopkins University. Professor Gostin is a Research Fellow and Visiting Professor at Oxford University and directs the WHO Collaborating Center on Human Rights and Public Health Legislation. Monica Das Gupta, M.Sc., Ph.D., is a Senior Social Scientist in the Development Research Group, The World Bank. She received her Masters degree in Demography at the London School of Economics in London, U.K., and her Ph.D. in Demography and Social Anthropology at the University of Sussex in Brighton, U.K. Max Levin, M.A., J.D. Candidate, is a third-year student at Georgetown Law and a Research Assistant at the O'Neill Institute for National and Global Health Law. He received joint M.A.s in International Affairs and Conflict Resolution from the American University of Paris and the Institut Catholique de Paris and currently works in the U.S. Department of Commerce's Office of Policy and Strategic Planning in Washington, D.C. 
ling public health needs such as assuring sanitation, nuisance abatement, occupational health and safety, and infectious disease control.

Another problem arises from the fact that public health agencies can be quite dependent on the judicial system to enforce compliance with health violations through the threat of civil litigation or criminal conviction. Litigation is an expensive process - even in the developed world. The U.S. faces caseloads that often dissuade prosecutors from pursuing all but the most serious crimes. In such an atmosphere, public health offenses are seen as small, and food and drug firms are wealthy and willing to expend resources to defend themselves. ${ }^{4}$ The expense of litigation can be onerous for developing country public health budgets.

The problem is further compounded by the slow and erratic judicial systems of some developing countries. These legal systems, in effect, do not constitute a credible threat for individuals and businesses that create health hazards and violate public health norms. In Nigeria, for example, there is a limited number of government officials with legal training and they are overburdened by non-health related cases (ranging from large-scale corruption to political vote-rigging scandals to murders by public vigilantes). ${ }^{5}$ Hence, public health violations are generally given a lower priority by government prosecutors. In addition, the tendency of the government to delay the payment of salaries to judicial officials leaves them vulnerable to corporate bribery. ${ }^{6}$

There are clearly many reasons to look beyond conventional litigation, and consider other approaches to regulation, which can offer insights into how developing countries with limited resources, limited administrative capacity, and slow judicial systems can implement public health regulations and standards. This article explores several modified and alternative implementation mechanisms being utilized in the Organisation for Economic Co-operation and Development (OECD) countries. Section II reviews the traditional regulatory powers possessed by public health agencies in OECD countries in the governance of persons and businesses. Section III discusses traditional approaches to regulatory implementation. Section IV discusses lower-cost strategies for implementing regulatory powers. Sections V and VI explores alternative methods of achieving public health compliance outside of the courtroom, including conflict resolution and public-private cooperation, followed by the conclusions.

\section{Public Health Regulation of Persons and Businesses}

Public health agencies typically possess an array of regulatory powers needed to implement health and safety standards within society. The regulatory mechanisms apply both to persons and businesses.

\section{Regulation of Persons}

In OECD countries, public health officials traditionally have held a variety of powers to control personal behavior for the prevention of communicable disease transmission. These regulatory measures include screening, reporting, treatment, vaccination, isolation, and quarantine.

Different countries vary in how far the law goes in mandating these measures. In some nations, measures such as screening and vaccination are completely voluntary; in other nations, these measures can be compulsory. Still other nations seek to find a middle ground between these two extremes. The Canadian government, for example, encourages vaccination by making public services conditional upon it; in Canada (as in many OECD countries), parents must present proof of their child's vaccination in order to register their child for public school. ${ }^{7}$ Such a method impels compliance with public health norms without infringing on civil liberties. Vaccinations, as a regulatory mechanism, are considered one of the most cost-effective and widely used public health interventions against infectious diseases.

Screening and reporting are useful methods to identify disease within a population and enable subsequent control measures for the protection of the public's health. ${ }^{8}$ The use of this mechanism can range from compulsory to fully voluntary (upon request), with intermediate gradations. For example, OECD countries typically mandate screening of schoolchildren or health workers for specific diseases (e.g., tuberculosis) as a condition of school or work.

Another common regulatory mechanism in the OECD countries is the mandatory treatment of persons diagnosed with an infectious disease. Public health statutes may authorize public health officials to require treatment of individuals "if they pose a significant risk of transmission and the treatment is beneficial."9 If a public health agency seeks to compel treatment adherence, it will often go through a process of escalating control measures whereby the use of more stringent measures must be justified based on public health need.

Two other common public health mechanisms are isolation and quarantine, which both involve the detention of persons but for different reasons. Isolation detains people who are known to have a communicable disease whereas quarantine detains asymptomatic people who are suspected to have a disease due to exposure. During the SARS and Influenza (A) H1N1 outbreaks, for example, countries used quaran- 
tines in a variety of settings (e.g., home, work, hospital) with different levels of coercion or enforcement.

\section{Regulation of Business}

Public health officials in the OECD countries also possess the ability to regulate businesses, including occupational health and safety, emission standards, hygiene, and sanitation. Such powers are critical to ensure that businesses behave in a safe and competent manner and do not create undue health risks. Regulatory powers include: licensing of trades, professions, and institutions; inspecting for violations of health and safety standards; and abating public nuisances.

Licenses are used to allow a business (or a profession) to engage in an activity that would otherwise be barred by law, and it typically requires the demonstration of proficiency in that activity. Public health agencies often utilize this mechanism to protect the public's health or safety through the requirement that certain standards are met in the performance of an activity. For example, OECD countries often issue licenses to qualified individuals in the practice of professions (e.g., doctors) as well as businesses in the operation of establishments (e.g., restaurants). ${ }^{10}$

Inspections are another useful mechanism that can be used to monitor and enforce compliance with health and safety standards in businesses. An inspection is an official investigation or oversight - a formal and careful examination of a product, business, or premises to ascertain its authenticity, quality, or condition. This mechanism is often utilized in the OECD countries to determine whether conditions exist that are deleterious to health and safety and thereby violate public health standards or rules.

In many jurisdictions - particularly those that derive from the common law legal system - public health officials can use the law of public nuisance to address potential health threats and poor safety standards. The definition of public nuisance tends to be quite broad; for example, under U.S. law, it includes anything injurious to health. Nuisances can range from "matters of significant annoyance to conditions that impose significant risks to health and safety," which include scenarios where businesses (or even private individuals) create pollution, contamination, or infestation..$^{11}$

This article focuses primarily on approaches to the regulation of businesses.

\section{Traditional Methods of Regulation}

Traditional methods of implementing public health regulations include mechanisms for monitoring, inducing compliance, and "punishing" non-compliance. The most common methods are through searches, inspection, and licensing. These forms of "traditional regulation" have a long-established history in the OECD countries. ${ }^{12}$

\section{Administrative Searches and Inspections}

Administrative inspections can be used to enforce public health standards. For a minor violation, the health agency might respond with a formal notice of health violation, but for more serious violations, the agency might go so far as to close the business. Many countries impose minimum inspection requirements on licensed individuals and companies. In Ireland, public health law mandates health and environmental inspections at least once per year. Regular inspections are costly, but save health resources in the long term by maintaining high public health standards and preventing hazardous practices. ${ }^{13}$

There are a few types of administrative inspection that public health agencies can perform. The simplest "walk-through" inspection provides a quick assessment of a facility, in which the public health inspector can observe operational practices, make sure that basic public health standards are being met, and check that records are being kept. ${ }^{14}$ Walk-through inspections can be a simple way of maintaining compliance with health laws because the inspection makes the presence of the public health authority felt by the company, which tends to induce compliance. A detailed compliance assessment is a more thorough inspection of records, interviews with staff, and examination of self-monitoring practices. In cases of non-compliance, the agency would collect evidence of public health violations, which could later be used as evidence in litigation..$^{15}$ A final type of inspection is a sampling inspection, which can be expensive and time-consuming, as many forms of sampling require more tools, scientific expertise, and resources. These could be difficult for many local public health agencies in some developing countries. Other forms of sampling can be fairly simple, such as testing salt for iodine content.

There are two main difficulties with inspections. First, government inspections call into question the fundamental civil liberties of some cultures. In the U.S., citizens enjoy a constitutional right to be protected from "unreasonable search and seizure," which is meant to ensure that citizens have the right to be secure in their own property. This constitutional right creates certain boundaries that government inspections may not infringe upon. Nevertheless, inspections span the entire field of public health-related law, ensuring the safe construction and maintenance of buildings or residences, purity of food and drugs, sanitary condition of farms or restaurants, safe workplace environments, and control of pesticides and 
toxic emissions. The U.K. deals with individual rights by placing firm limits on the government's right to inspection. Inspections are often limited to "reasonable hours" or "with notice," or to particular hours of the day. Inspection powers, however, are still significant because they allow for entry without a warrant when inspections are conducted for the purposes of public health protection. ${ }^{16}$

The second difficulty is that inspections can be an expensive form of regulation. Inspections take significant time, require trained workers, and can be subject to graft. All three problems risk being exacerbated in developing countries where resources are at a premium.

\section{In creating a licensing system, governments must be careful not to set unrealistic administrative demands on local agencies. Without adequate funding and oversight, a licensing system can be ineffective and even lead to abuse.}

\section{Licenses}

Licensing can be a highly effective approach to regulating potentially unsafe behavior. This approach serves a two-fold purpose in public health regulation. First, a licensing system - by requiring proof of competence and compliance with minimum standards - can sift out the unqualified business and unsafe practices. Second, through inspections and sanctions for violators, licensing offers continuous public health monitoring and supervision. In the OECD countries, licensure generally allows flexible enforcement by public health officials. For example, in Australia, health officers who detect poor hygiene by a food vendor have several options: prosecution, a default notice, or a "clean up" order. In some states within Australia, such as New South Wales, failure to comply with the first order may lead to a second order that would prohibit the sale, handling, or manufacture of food on the premises. ${ }^{17}$ Similarly, in the U.S., the Food and Drug Administration (FDA) can issue a license suspension that is "effective immediately, with a right of hearing only upon the firm's request for reinstatement under a new permit." 18 These strategies allow agencies to respond flexibly to health threats.

Though the licensing system provides many benefits, there may be drawbacks for the developing world. Despite licensure's flexibility and effectiveness, it can be an "administratively expensive and cumber- some enforcement tool."19 This is of particular concern where agencies are chronically short of funds (and/or licensing procedures are unnecessarily cumbersome and transaction-intensive) because proper monitoring can easily be pushed aside in favor of expediency and graft. In creating a licensing system, governments must be careful not to set unrealistic administrative demands on local agencies. Without adequate funding and oversight, a licensing system can be ineffective and even lead to abuse.

Another problem is that, in some developing countries, underpaid government officials can be tempted to use licenses as a tool for extortion. ${ }^{20}$ Most OECD countries have built, over many years, a series of internal checks on government authority (such as a public complaint process, public ombudsmen, administrative review, and judicial oversight) to address such problems. Citizens who feel that they have been harassed by government authorities have recourse through a variety of structures. In countries that dedicate fewer resources to checking government authority, concerns about harassment can be substantial, and careful measures need to be put in place to enhance transparency and accountability in the regulatory process.

\section{Overcoming the Limits of Traditional Regulation}

The administration and enforcement of public health regulations are highly resource intensive tasks that can be difficult for developing countries due to limited agency capacities, poorly designed procedures for regulatory implementation, and unreliable judicial systems. Although traditional mechanisms such as licensing and inspections are vital to public health, many OECD agencies have started to supplement these methods with less cumbersome and expensive approaches in recent years. In particular, agencies have adopted the use of formal notice, public disclosure, and cascading sanctions to lower costs and improve compliance. Such approaches to reducing the costs of regulatory implementation might be useful for developing countries to adapt to their own circumstances.

\section{Formal Notice}

Written notices of health violations offer a highly cost-effective way to enforce health regulations. These notices are usually simple; their job, in the words of one U.S. FDA manager, is to tell the company to "knock it off!" More formally, the FDA describes a warning letter as "a legally significant notice...by the FDA, that a per- 
son is believed to be in violation of laws or regulations enforced by the FDA."21 Since warning letters do not carry any force of law, they do not require any official collection of data by the health agency. If the company in question feels that it has done nothing wrong, they can dialogue with the agency in an attempt to resolve the problem. But the warning letter serves as notice that the agency believes there is a violation and that if the company does not change its behavior, legal action "surprisingly effective" in achieving regulatory goals without coercion. ${ }^{23}$ Public disclosure can take the form of product labeling, health warnings, conflict of interest statements, health outcomes data, adverse event reporting, and product safety information.

There are many potential uses of public disclosure. The threat of public disclosure can compel companies to change product design, since the threat of disclosing harmful ingredients often makes companies nervous

\section{Licenses and inspections are more effective enforcement mechanisms, but also more expensive to administer. Written notices and public disclosure are less costly to use, but they are impotent without a credible threat of real sanctions. Thus, the most effective way to use these approaches is in combination as a "cascading hierarchy of sanctions."}

could follow. Warning letters also serve the alternative purpose of establishing evidence for any future trials that a person's or company's actions were taken "in defiance of well-understood proscriptions." ${ }^{22}$

The FDA has found that written notices can be a particularly effective way to induce compliance with health regulations and standards, especially when used in conjunction with public disclosure (see below). For example, the FDA can issue a warning letter to an offending company that is suspected of selling a misbranded drug. As a next step, the FDA can threaten legal action or public disclosure in exchange for the company's agreement to remedy the problem. A recent example of the simplicity of the FDA's use of this strategy occurred in 2006 when the FDA began requiring food companies to list trans fat content separately on the Nutrition Facts panel of all packaged foods. Though the FDA does not regulate trans fat in foods, the simple act of informing companies that their products would be displayed as containing trans fat content was enough to induce change in a number of companies. These companies reduced the trans fat content in their products to below the minimum amount per serving so that they could they could label their products "trans fat free" on the packaging.

\section{Public Disclosure}

Public disclosure is an efficient and straightforward way of enforcing compliance with public health regulations. Public health agencies can require companies to give them information on certain activities (such as pollution levels) and then release that information to the public. The resulting public pressure on the company (or even the threat of public pressure) has been enough to improve their product. Or public disclosure can be used to encourage honest dealings. In the U.S., the FDA requires drug companies to disclose all financial transactions made between the company and any clinical investigators. Public disclosure can caution consumers about the hazards of products and educate consumers about safe uses of those products. It can encourage safer professional practices by helping the public to monitor health behavior; public disclosure of the performance of physicians, hospitals, and managed health-care plans provide a good example of this tool. Public disclosure can even be used as a lower-cost (though less effective) way of conducting an inspection, since asking for the information in itself may induce the sort of improvements that inspections are meant to compel.

Public disclosure can be a powerful way of increasing administrative authority at low cost, and without imposing on civil liberties. The public health agency need not coerce nor waste valuable resources; it simply brings information out into the light of public scrutiny where public opinion can pressure companies into reforming their behavior. Unlike some forms of regulation, there is little political backlash from public disclosure. In most OECD countries, consumers and patients are thought to have an undisputed right to be fully informed in making their public health decisions. Public disclosure does not compel companies to alter products or design; it merely increases transparency to potential consumers. Finally, the low costs of public disclosure make it a useful mechanism for developing countries facing limited agency capacity. Because it does not increase monitoring costs, public disclosure is a low-cost approach to 
public health regulation that can be implemented by developing country governments.

\section{A Cascading Hierarchy of Sanctions}

All of these implementation strategies have their strengths and weaknesses. Licenses and inspections are more effective enforcement mechanisms, but also more expensive to administer. Written notices and public disclosure are less costly to use, but they are impotent without a credible threat of real sanctions. Thus, the most effective way to use these approaches is in combination as a "cascading hierarchy of sanctions."

In a cascading hierarchy of sanctions, the public health agency addresses a public health problem in a series of steps, to induce compliance with minimal resort to the more extreme measures. The first step usually takes the form of a voluntary measure. In the case of a food vendor practicing improper hygiene, the first step would be simply to explain to the vendor how to improve food hygiene. If the matter is not resolved within a specific period, the agency moves on to the next step, issuing a formal notice, asking the vendor to remedy the situation. Such a notice would state the specifics of the violation and make it clear that if the vendor does not remedy their practices, more severe action will follow. If again, the matter is not resolved, the agency responds by imposing a fine and sending a second notice demanding that the agent remedy the situation. If the vendor still fails to rectify the problem, then the agency should make the issue public by forcing the restaurant to publicly disclose its sanitation practices and any risks to the public's health. Finally, only as a last resort, would the agency take the administratively expensive steps of formal inspection, withdrawing the vendor's license, or prosecuting the vendor.

At any of these stages, the vendor can appeal against perceived harassment by taking his complaints to an ombudsman or mediator. The judiciary becomes involved only if the vendor decides to appeal to the court as a last resort. But, even here, the vendor is deterred from this. In the course of dealing with the vendor, the public health agency has accumulated a large amount of formal evidence. This evidence will make successful prosecution of the case a much simpler matter and the vendor will likely be deterred from attempting to litigate the issue since he is unlikely to win. This strategy not only minimizes the number of resources that must be immediately committed to combat a standard public health violation; it also minimizes the chances that the case will come before a court. The administrative agency is able to take a number of escalating steps - none of them very costly
- that can address the restaurant's behavior at a minimal cost to both parties.

Of course, these simpler measures work better if backed by a credible threat of sanctions in the case of repeated noncompliance. Unfortunately, the ultimate threat is often that of judicial action, which can lack credibility if the process is slow and unpredictable. The next section discusses some alternate approaches to judicial action.

\section{Efficient Conflict Resolution}

Overcrowded and inefficient courts are not a problem unique to the developing world. In many OECD countries, legal dockets are over-crowded, with long case backlogs and underfunded government prosecutors. As a result, public health agencies have begun to employ non-judicial techniques to resolve disputes arising in public health administration. These techniques usually involve less costly and time-consuming processes than do court cases.

\section{Alternative Dispute Resolution}

Alternative dispute resolution (ADR) is an approach that attempts to settle disputes outside of the government judicial system. It relies on methods such as negotiation, mediation, or arbitration to resolve disputes between parties. Arbitration and mediation accomplish many of the same objectives as a standard court trial, but provide some added benefits in increased efficiency. Arbitration is similar to a standard legal trial; however, instead of the case being heard by a judge and conducted according to the formal rules of the legal system, the dispute is argued in a less formal setting and decided by a mutually acceptable arbiter (often an expert in the field). Such disputes are typically resolved more quickly and with less expense than a standard court trial. And since both sides have explicitly agreed to be bound by the arbiter's decision, there is generally less dissatisfaction with the outcome.

Like arbitration, mediation is a more cost- and time-effective means to settling a dispute. In mediation, the parties to a given dispute gather and negotiate (with the help of a mediator) a mutually acceptable resolution to the dispute. Mediation provides the added benefit of encouraging compromise and mutual understanding among parties, a fact which often leads to better relations and fewer recurrences of conflict.

A recent dispute in Germany is representative of alternative dispute resolution's growing role in OECD health and environmental conflicts. In the tiny village of Münchehagen in Lower Saxony, local citizens and the district public health agency became concerned about a hazardous waste landfill. It was suspected 
that local industry (aided by a lax municipal authority) was responsible for illegal dumping in the landfill, which led to the contamination of the village's soil and water and was posing a danger to public health. ${ }^{24}$ Conflict over the landfill arose between the local citizens and the district public health agency on one side and local industry on the other side, but the parties agreed to resolve their dispute through mediation. A public health official trained in mediation was brought in from a neighboring province to help resolve the dispute, and this led to mediation negotiations involving representatives from local authorities, environmental organizations, state government, and concerned members of the public. The procedure was financed by the health and environmental agency which agreed to keep the public regularly informed about the negotiations. These negotiations are felt to be a strong success story on the power of mediation as numerous agreements have been reached on questions of technology and the extent of the clean-up and the committees have continued to meet afterwards to monitor implementation and discuss future issues. Perhaps most importantly, mediation has been a much cheaper option than a standard court trial, saving the parties vast sums of time and attorney fees. ${ }^{25}$

Austria has been a pioneer in encouraging mediation in public health and environmental conflicts. In some cases, local public authorities may suspend general administrative procedures in order to conduct mediation. According to a study by the Austrian Society for Environment and Technology, the benefits of these mediation proceedings were impressive. Most mediation proceedings were concluded within one year. For larger projects, the costs of mediation were estimated at $.01 \%$ of the total project cost; for small projects, the costs were between 1-10\% percent. The mediation costs were borne either by the party responsible for the project, or jointly by government bodies. ${ }^{26}$

Such success stories have led to the growing use of alternative dispute resolution mechanisms in OECD public health agencies. Alternative dispute resolution is perhaps the fastest growing trend in administrative law today. ${ }^{27}$ In New South Wales, Australia, the Health Commission provides mediation programs that divert disputes away from the litigation system. ${ }^{28}$ In France, government and scholars both promote alternative dispute resolution as a means of "relieving the burden of the courts, and resolving disputes in a faster, simpler, and cheaper manner."29 In administrative disputes in particular, mediation has become an increasingly frequent approach to resolving conflicts between administrators and businesses or persons. Even in Germany, where "virtually all major (environmental and health) disputes until recently ended up in court," the trend towards alternative dispute resolution has increased, as both companies and local NGOs have realized the economic and social benefits. ${ }^{30}$

Alternative dispute resolution is not by any means a strictly Western construct. In fact, alternative dispute resolution is experiencing rapid growth in Asia, where many countries have been quick to realize the gains in legal efficiency and effectiveness that alternative dispute resolution can bring. ${ }^{31}$ The China International Economic and Trade Arbitration Commission has administered more international arbitration cases than any other institution in the world over the past few years. But international alternative dispute resolution's growth in China has organic roots, as China has enacted sweeping reforms and updates to its alternative dispute resolution system, allowing it to play a larger role in domestic law. Under the new reforms, "domestic arbitration is to be handled by commissions established at the municipal level which are independent of and not subordinate to any government or administrative body." ${ }^{2}$ In this new system, each local arbitration commission is a member of the newly formed China Arbitration Association, an independent organization that supervises its own arbitrators and provides a set of model procedural rules. ${ }^{33}$

Like many non-traditional approaches to regulation, alternative dispute resolution has significant potential in developing countries. Alternative dispute resolution is much cheaper than adjudication through the traditional legal system where long, expensive trials can cause both sides of the dispute to end up worse-off than before. Furthermore, alternative dispute resolution provides a better opportunity for both parties to walk away on cordial and mutually beneficial terms than the adversarial court system (where it is rare that a court ruling will satisfy all parties to the conflict). It may also dovetail with local practices: for example, historically, in common law countries, a panel of industry experts familiar with standard practices and dealings often helped settle business disputes. ${ }^{34}$

\section{Ombudsmen}

Many OECD countries have agency Ombudsmen whose job is to act as a trusted intermediary between the people and government agencies. These Ombudsmen serve a watchdog role to identify government abuses and act in a "mediator-like" capacity to negotiate differences. Ombudsmen cannot be removed from office, a fact that enables them to represent the people in disputes with government, while insulating them from political pressures.

The U.K.'s Health Service Ombudsman is typical of the kind of intermediary that OECD nations employ to guard against agency abuses. In recent years, the 
U.K. Health Service Ombudsman has brought cases against government missteps on diverse issues such as environmental violations, and the discriminatory distribution of health services. Many of these cases have resulted in improved health administration. For example, in 2003, the Health Service Ombudsman brought a case against the government for denying health services to certain disabled and elderly citizens after receiving numerous complaints. The government eventually agreed to pay out a large sum in restitution and promised to review its actions and take greater precautions to avoid repeating the same mistake. ${ }^{35}$

Most OECD countries have an Ombudsman or mediator capable of confronting the government over perceived abuses. These Ombudsmen play an impor-

\section{Public-Private Cooperation}

Industries operate to maximize profits, and this goal can conflict with public health objectives. Hence, the control of businesses is a critical issue for public health agencies. This, unfortunately, seems like an impossible task for health agencies faced with limited administrative capacity and the inability to prosecute these companies in court. An alternative solution that has surfaced in recent years is the use of publicprivate cooperation. In this case, health agencies try to collaborate with the private sector in drafting and implementing public health policies (or objectives) together. This method, although imperfect, provides a practical means through which public health agencies can achieve their objectives in resource poor governments.

\section{An alternative solution that has surfaced in recent years is the use of public-private cooperation. In this case, health agencies try to collaborate with the private sector in drafting and implementing public health policies (or objectives) together. This method, although imperfect, provides a practical means through which public health agencies can achieve their objectives in resource poor governments.}

tant role in making sure that citizens' public health complaints are heard. In Ireland, for example, $14 \%$ of complaints related to public health. ${ }^{36}$ Some OECD countries, such as Norway, have specialized "Health Ombudsmen" whose job is to watch over public health abuses. To prevent the Ombudsman from being overburdened, each of Norway's regional governments has its own Ombudsmen to watch over public health and social affairs in that region. These Ombudsmen can take a case either at their own initiative or at the request of an interested party. ${ }^{37}$

Ombudsmen could have an important role in developing countries. Where judicial processes are slow and erratic, public health administration is difficult, but so is recourse against administrative abuses. ${ }^{38}$ If courts cannot prosecute quickly or efficiently, the common citizen has even less of a chance of efficient resolution. Mistaken or oppressive government actions escape scrutiny and civil liberties can be lost. ${ }^{39}$ It is therefore important that developing countries, like developed ones, have a strong, independent Ombudsmen or mediators to protect these civil liberties watch against government neglect or abuse.

\section{Negotiated Rulemaking}

Negotiated rulemaking is "a voluntary process to promote interactive participation in drafting regulations." ${ }^{\prime 0}$ Sometimes known as regulatory negotiation or "reg-neg," negotiated rulemaking has been effective in settings where government faces limitation in regulating public health violations. By changing the traditional roles from that of regulator and regulatee to a more complex relationship, in which the interested parties negotiate collectively the text of a proposed rule, this approach can be less adversarial than traditional regulation. ${ }^{41}$ The negotiators make trade-offs, evaluate priorities, and come to understand the position of the other parties. ${ }^{42}$

For example, in the Netherlands, the Rotterdam city government contracts with companies upriver to stop polluting the Rhine River. Since the city is situated in an "end-of-pipe" position at the estuary of the Rhine River where toxic material is dumped in the river by upstream industries, the Rotterdam government has negotiated environmental "covenants" with the Dutch, German, and French upriver polluters to stem pollution. According to these contracts, the government agrees to a certain attitude toward the environmental conduct of the other private party (e.g., to refrain 
from imposing further regulations upon the company) while the private party agrees to limit or refrain from polluting. The government acts as a private party under these contracts and waives the right to sue the company over damages caused by pollution into the public harbor. Essentially, the government assumes a role that is akin to that of a manager of the harbor and negotiates a fair agreement with polluters. ${ }^{43}$

The upshot of such an agreement is that the government spends fewer resources policing the industry. Ideally, negotiated rulemaking will transform the relationship between government and industry from one of mutual suspicion and hostility to one of greater cooperation. When companies or persons are given a seat at the negotiating table, there is an opportunity to reach a mutually agreeable arrangement and, hence, these actors are more likely to comply with the ensuing agreement. Through this process, the government learns to better understand industry's concerns and is able to design a health policy that lessens harmful practices while trying to accommodate industry needs. The benefits of negotiated rulemaking include: reduced time and resources in required for the development of rules, faster implementation of those rules, greater compliance, less litigation, and more cooperative relationships. ${ }^{44}$ In addition, in locations where human and financial regulatory resources are limited, there may be practical benefits in the cooption of private expertise.

Critics of regulatory negotiations assert that negotiated rulemaking may lead the agency to "abandon its role as the guardian of the public interest by yielding to the interests of powerful stakeholders." ${ }^{45}$ This is a valid concern as there are situations where traditional forms of government regulation, free from private sector influence, are necessary. Public health agencies must strive to establish and implement regulations that protect the public's health as its foremost concern. Nevertheless, there is a strong argument for use of regulatory negotiations in the developing world in some situations for the sake of health progress at the cost of minimal trade-offs rather than an absolutely intractable state.

\section{Self-Regulation}

Self-regulation is another technique that public health agencies can use to encourage and improve compliance without significant expenditures. This approach is intended, in principle, to be a voluntary means of achieving cooperative action without direct state intervention; although, in practice, external intervention is often involved ${ }^{46}$ In the OECD countries, selfregulation has been applied for public health purposes in a variety of areas ranging from advertising to worker and product safety, environmental management, and fire prevention. These forms of self-regulation are useful, to some extent, in improving public health.

There are three primary approaches to self-regulation: voluntary self-regulation, whereby standards formulation and enforcement are conducted privately; mandated full self-regulation, whereby regulation is privatized, but the government monitors and, in some cases, intervenes in enforcement to ensure compliance; and mandated partial self-regulation, whereby the government either enforces compliance with private standards or mandates the private enforcement of public rules. ${ }^{47}$ The use of the self-regulatory approach can take the forms of codes of conduct, industry standards, accreditation, and ratings, ${ }^{48}$ and public officials need to work in concert with self-regulating agencies to draft these.

Codes of conduct set out specific standards of conduct for an industry which dictate what is acceptable and required behavior. ${ }^{49}$ For example, Medicines Australia is a self-regulatory industry association that sets the standards for the ethical marketing of pharmaceutical products in Australia. ${ }^{50}$ Effective codes of conduct improve compliance with regulation and increase consumer protection at a minimal cost to the government. Companies receive several benefits from complying with such codes: greater transparency among the industry; improved investor confidence in the business; a competitive marketing advantage; and a greater sense of ownership of the code leading to a stronger commitment. ${ }^{51}$ Such codes of conduct may not be as stringent as direct government regulation, but they are a vast improvement on the non-existent government regulation that sometimes exists in developing countries. As such, codes of conduct have become increasingly common in many nations. By protecting against false claims and improper relationships between drug companies and health care professionals, these codes preempt marketing practices that might harm public health.

Another form of quality control is mandated by the government, but carried out by the regulated party or another private entity. An example of this model is employed in Germany, where blood banks are required to test donated blood for diseases that can be transmitted by transfusion. If a unit of blood is unsafe, it cannot be distributed and the donor must be notified. ${ }^{52}$

Another method of self-regulation is for industry to create minimum standards in product design that companies must comply with in order to receive accreditation. Accreditation is similar to licensing, but instead of the government monitoring and issuing licenses, a private organization (such as an industry 
association) issues credentials to companies that meet a specified set of design or safety standards. ${ }^{53}$

Through measures such as licensing or accreditation, self-regulation associations can exert a large impact on industry compliance with public health objectives; specifically, standards of competence, safety, or design. In addition, the negative publicity of losing such accreditation provides a major incentive for these companies to conform to industry standards. Government sanctions, in some instances, can give self-regulation the force of law. For example, if a hospital wishes to participate in a U.S. government health-care program, it must be accredited by the Joint Commission for the Accreditation of Hospitals, a self-regulatory body. ${ }^{54}$ Self-regulation also provides many of the same advantages of negotiated rulemaking. Well-constructed industry self-regulation can provide for speedy implementation, greater flexibility, less burden on government, and reduced political opposition. ${ }^{55}$

Examples of industry self-regulation in OECD countries are abundant. For example, in the U.S., associations representing the alcohol industry require advertising to reach an audience composed of more than 50 percent adults. ${ }^{56}$ As children's health issues have come to dominate public health discourse in recent years, the American Beverage Association issued guidelines to remove the sale of full-calorie soft drinks in schools, ${ }^{57}$ while five large snack food manufacturers agreed to an initiative to discourage schools from stocking vending machines with unhealthy foods. ${ }^{58}$ In Canada, a self-regulating organization - Advertising Standards Canada (ASC) - compels responsible advertising from food and beverage companies. ${ }^{59}$

Private companies can, in certain situations, be effective regulators. Wealthy companies and institutions have more resources with which to monitor and regulate other industry members. What is more, it is in their economic and competitive interest to do so. If a particular company profits by breaking the rules, then those compliant companies who are abiding by the rules are not only well-situated to discover this foul play, and these companies have every reason to band together to put a halt to this undesirable practice.

Finally, ratings, like accreditation, can be used by public health agencies to pressure companies into conforming to public health and safety standards. Privately run independent organizations, such as the U.S.'s Consumer Reports, publish unbiased ratings and reports on everything from automobile safety to drug safety, create ratings to encourage companies to produce safer products for consumers and, in consequence, protect the public's health. ${ }^{60}$
Self-regulation has many advantages, especially in terms offering a lower-cost alternative to traditional forms of regulation. However, there are many flaws in this policy. Self-inspection is a shaky solution even in OECD countries with a long tradition of self-regulation. In some developing countries, a system of self-inspections risks turning self-regulation into no regulation without some government oversight. Selfregulation is not meant to entirely remove the threat of monitoring or inspections, because some monitoring is still needed. The government should retain this power. But by encouraging strong self-regulating agencies, the government can lessen its regulatory burden by delegating some of this work to an independent institution.

\section{Public-Private Cooperation in Designing and Implementing Public Health Laws}

The inclusion of a wide array of participants in the public health law development process is pivotal. Participants such as the community, civil society organizations, and private businesses can provide valuable, and perhaps unforeseen, advice and input. It is also important to include other sectors (such as the agencies for environment, safety, emergency relief, etc.) in order to achieve synergistic policies that will help to benefit public health and other areas for the common good. By allowing local groups to provide a hand in the negotiation and establishment of new health standards, public health agencies can both improve compliance and help to soften the wave of often tumultuous changes that globalization carries to these societies.

Transparency is another key factor to the effective implementation of public health laws. The use of public announcements, open forums (e.g., town halls and community gatherings), and public comment sessions (e.g., requests for information) are mechanisms that can help dispel potential concerns of suspicion or mystification that might surround the development of public health laws. Transparency will foster trust, confidence, and appreciation in the efforts of public health agencies, which will be crucial for public and private cooperation during the implementation phase.

\section{Conclusions}

There are a number of ways to reduce the costs of assuring compliance with public health standards. This article sought to shed light on various OECD approaches to this problem through a review of traditional and innovative legal mechanisms, which help implement public health regulations at lower cost, with greater transparency, and reduce dependence on the judiciary. The suggestions here are not intended to provide a one-size-fits-all solution to public health 
regulation in the developing world. Developing countries build from their own unique institutional foundations; they operate in the context of differing political atmospheres; and they face their own sets of problems. The mechanisms suggested here, such as mediation or negotiated rule-making, might be particularly well-suited for some purposes where they can tap into strong traditions of community rule-making, while the mainstream incentive-based forms of regulation might be more applicable for most other purposes. Essentially, these approaches will have to be adapted as needed to suit the particular health needs, institutional contexts, and resource availabilities of low-income countries.

Note

The views in this paper are those of the authors, and should not be attributed to the World Bank or affiliated organizations or member states.

\section{Acknowledgements}

This research was supported by the World Bank's Governance and Anti-Corruption Trust Fund. The authors thank Alix Pereira for input and editing and Seth Pardee for research assistance.

\section{References}

1. Institute of Medicine, The Future of Public Health (Washington, D.C.: National Academic Press, 1988).

2. L. O. Gostin, Public Health Law: Power, Duty, Restraint (Berkeley: University of California Press, 2008): at 16.

3. Id.

4. J. T. O'Reilly, Food and Drug Administration (Colorado Springs, CO: McGraw-Hill, Inc, 1992): at 6-3.

5. D. J. Smith, A Culture of Corruption: Everyday Deception and Popular Discontent in Nigeria (Princeton: Princeton University Press, 2007): at 166-190.

6. Id.

7. T. M. Bailey, T. Caulfield, and N. M. Ries, Public Health Law and Policy in Canada (Markham, Ontario: Lexis Nexis, 2008): at $148-153$.

8. M. A. Stoto, D. A. Almario, and M. C. McCormick, Reducing the Odds: Preventing Perinatal Transmission of HIV in the United States (Washington, D.C.: National Academies Press, 1999): at 21-35.

9. See Gostin, supra note 2, at 415 .

10. L. O. Gostin, F. E. Thompson, and F. P. Grad, "The Law and the Public's Health: The Foundations," in R. A. Goodman, R. E. Hoffman, W. Lopez, G. W. Matthews, M. A. Rothstein, and K. L. Foster, eds., Law in Public Health Practice (New York: Oxford University Press, 2007): at 25-44; R. Martin and L. Johnson, Law and the Public Dimension of Health (London: Cavendish, 2001); American Medical Association, State Medical Licensure Requirements and Statistics (Chicago: American Medical Association, 2006).

11. See Gostin, Thompson, and Grad, supra note 10, at 18.

12. See Gostin, supra note 2, at 463-473.

13. A. Farmer, Handbook of Environmental Protection and Enforcement: Principles and Practice (Sterling, VA: Earthscan, 14. Id.

15. Id.

16. See Martin and Johnson, supra note 10, at 75-95.

17. C. Reynolds, Public Health Law in Australia (Sydney: Federation Press, 1995): at 112-113.
18. See O'Reilly, supra note 4, at 6-9.

19. See Martin and Johnson, supra note 11, at 88.

20. See Smith, supra note 5, at 57-87.

21. See O'Reilly, supra note 4, at 6.4.

22. Id., at 6.5.

23. R. Seerden, Administrative Law of the European Union, Its Member States and the United States: A Comparative Analysis (Antwerpen: Intersentia, 2001): at 362.

24. C. Napier, Environmental Conflict Resolution (London: Cameron May, 1998): at 71.

25. Id.

26. N. Alexander, Global Trends in Mediation (Fredrick, MD: Aspen, 2006): at 74-76.

27. Id., at 1-4.

28. Id.; C. Reynolds, Public Health Law and Regulation (Sydney: Federation Press, 2004).

29. T. E. Carbonneau, J. Jaeggi, and S. K. Partridge, Handbook on International Arbitration and Alternative Dispute Resolution (Huntington, NY: Jurisnet, 2006): at 265.

30. See Napier, supra note 24, at 69 .

31. See Carbonneau, Jaeggi, and Partridge, supra note 29, at 275. 32. Id., at 253 .

33. Id.

34. L. M. Friedman, A History of American Law (New York, NY: Touchstone, 2005).

35. U.K. Parliamentary and Health Service Ombudsman, NHS Funding for Long-Term Care: Follow Up Report, U.K. Parliamentary and Health Service Ombudsman Website, available at <http://www.ombudsman.org.uk/_data/assets/ pdf_file/0014/1076/NHS-funding-for-long-term-care-followup-report.pdf $>$ (last visited June 25, 2010).

36. Office of the Ombudsman Ireland, Annual Report of the Ombudsman (2006), available at <http://www.ombudsman.gov.ie/en/Publications/AnnualReports/AnnualReportoftheOmbudsman2007/> (last visited June 18, 2010).

37. K. Graver, "A Study of the Consumer Ombudsman Institution in Norway with Some References to the Other Nordic Countries I: Background and Description," Journal of Consumer Policy 9, no. 1 (1986): 45-60.

38. See Smith, supra note 5, at 112-136.

39. Id.

40. See Gostin, supra note 2, at 173.

41. P. J. Harter, "Negotiated Regulations: A Cure for Malaise," Georgetown Law Journal 71, no. 1 (1982): 1-118.

42. C. M. Kerwin, Rulemaking: How Government Agencies Write Law and Make Policy (Washington, D.C.: CQ Press, 1994).

43. J. Glazewski and G. Bradfield, Environmental Justice and the Legal Process (Cape Town: Juta \& Co, Ltd., 1999).

44. D. M. Pritzker and D. S. Dalton, Negotiated Rulemaking Sourcebook (Washington, D.C.: Administrative Conference of the U.S., 1995).

45. See Gostin, supra note 2, at 174 .

46. N. Gunningham and J. Rees, "Industry Self-Regulation: An Institutional Perspective," Law and Policy 19, no. 4 (1997): $363-414$, at 365 .

47. $I d$.

48. See Gostin, supra note 2, at 175.

49. Australia Competition \& Consumer Commission, Guidelines for Developing Effective Voluntary Industry Codes of Conduct, Commonwealth of Australia, 2005.

50. Medicines Australia, Codes of Conduct, 2006, Medicines Australia website, available through <http://www.medicinesaustralia.com.au/pages/page5.asp> (last visited June 18, 2010).

51. See Australian Competition \& Consumer Commission, supra note 49.

52. L. Gable, K. Gamharter, L. O. Gostin, J. G. Hodge, and R. V. Van Puymbroeck, Legal Aspects of HIV/AIDS: A Guide for Policy and Law Reform, (Washington, D.C.: The World Bank, 2007).

53. J. P. Cioffi, M. Y. Lichtveld, L. Thielen, and K. Miner, "Credentialing the Public Health Workforce: An Idea Whose Time Has 
Come," Journal of Public Health Management Practice 9, no. 6 (2003): 451-458.

54. T. Jost, "Medicare and the Joint Commission on Accreditation of Healthcare Organizations," Law and Contemporary Problems 15, no. 4 (1994): 15-45.

55. See Gostin, supra note 2, 175-1776.

56. Federal Trade Commission, Self-Regulation in the Alcohol Industry: A Review of Industry Efforts to Avoid Promoting Alcohol to Underage Consumers, September 1999, available at <http://www.ftc.gov/reports/alcohol/alcoholreport.shtm> (last visited June 25, 2010).

57. American Beverage Association, School Beverage Guidelines, 2006, available at <http://www.ameribev.org/nutrition-- science/school-beverage-guidelines/> (last visited June 25, 2010); C. E. Mayer, "Sugary Drinks to be Pulled from Schools: Industry Agrees to Further Limit Availability to Children," Washington Post, May 3, 2006.

58. D. B. Caruso, "Firms to Tout Healthy Snacks in Schools," Boston Globe, October 6, 2006.

59. The Canadian Code of Advertising Standards, Advertising Standards Canada, 2007, Advertising Standards website, available at $<\mathrm{http}: /$ www.adstandards.com/en/Standards/canCodeOfAdStandards.aspx> (last visited June 18, 2010).

60. Consumer Reports Health, "Our Mission," Consumer Reports Healthwebsite,2008, availableat<http://www.consumerreports. $\mathrm{org} /$ health/about/mission.htm> (last visited June 18, 2010). 